\title{
The orocraniodigital syndrome of Juberg and Hayward
}

Alain Verloes, Martine Le Merrer, Jean-Claude Davin, Philippe Wittamer, Charles Abrassart, Guy Bricteux, Marie-Louise Briard

\begin{abstract}
We report three new isolated cases of orocraniodigital syndrome (JubergHayward syndrome). The main clinical features of this unusual birth defect (six patients from three families described so far) are cleft lip/palate, hypertelorism, bowed and upward slanting eyebrows, thumb hypo/aplasia or proximal/distal thumb displacement, luxation of the radial head, elbow restriction, minor vertebral and rib anomalies, and horseshoe kidneys. New features observed in our patients are severe mental impairment (not correlated with the severity of the malformations), anterior anal displacement, and ptosis. Recessive inheritance is likely, but autosomal dominant inheritance cannot yet be totally ruled out; therefore, genetic counselling of parents of an affected child and of affected patients themselves must be cautious.
\end{abstract}

A new familial syndrome of oral, cranial, and digital anomalies was reported in 1969 by Juberg and Hayward. ${ }^{1}$ Since that time, only two other cases have been described. ${ }^{23} \mathrm{We}$ report here three new cases, as a contribution to the delineation of this uncommon syndrome.

Centre for Human Genetics, University Hospital, Liège, Belgium.

A Verloes

Clinic of Medical Genetics and INSERM U12, Hôpital des Enfants-Malades, Paris, France. M Le Merrer M-L Briard

Department of Pediatrics, University Hospital, Liège, Belgium. J-C Davin

\section{Department of} Pediatrics, Clinique St Joseph, Liège, Belgium. G Bricteux

Centre Hospitalier Huttois, Huy, Belgium. C Abrassart P Wittamer

Correspondence to $\mathrm{Dr}$ Verloes, Centre de Génétique, Pathologie B23, CHU Sart Tilman, B-4000 Liège, Belgium.

Received 25 March 1991. Revised version accepted 5 August 1901.

\section{Case reports}

CASE 1

This girl is the only child of non-consanguineous parents of Spanish/Italian origin. She was born in 1981 , at 40.5 weeks of a pregnancy complicated by IUGR (noted since the 18th week) and oligohydramnios. Birth weight was $1410 \mathrm{~g}$ ( $<<3$ rd centile), length $41 \mathrm{~cm}$, and OFC $29.5 \mathrm{~cm}$ ( $<<3$ rd centile). Physical examination included a triangular face, hypertelorism, unilateral fleshy tag near the corner of the mouth, low set lop ears, bilateral radial ray aplasia with shortened and inwardly bowed forearms, windmill-vane fingers, and crowded toes (fig 1). Radiographs showed fusion of D1$\mathrm{D} 2$, a supernumerary hemivertebra at the $\mathrm{L} 1$ level, and 13 slender ribs bilaterally. Right ureteral reflux with moderate pyelic enlargement was responsible for repeated UTI during infancy. She suffered atopic dermatitis. Developmental milestones were delayed: she stood at 9 months, walked at 3 years, and could hardly speak. At 9 years, she was $115 \mathrm{~cm}$ tall and had an OFC of $48 \mathrm{~cm}$. Her face was broad nasal bridge, arched eyebrows, epicantriangular, with bilateral ptosis, strabismus,

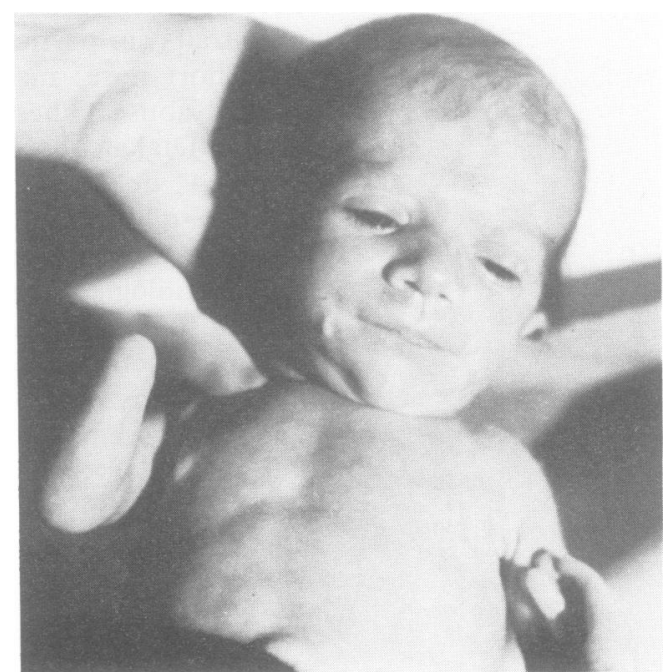

Figure 1 Patient 1 at 6 months: note hypertelorism.

thus, large, stubby nose, crowded teeth, short palate with a large but short uvula and submucous cleft, and somewhat cupped ears (fig 2). She wore a corset because of a severe dorsolumbar kyphoscoliosis convex to the left. Several surgical procedures were undertaken to straighten the forearms, to pollicise the index fingers, and to fix the carpal bones (fig 3) in a useful position. Echocardiography disclosed a raised left auricle/aorta ratio without anatomical defect. CT scan showed cerebral atrophy with enlarged ventricles (fig 4). Fundus examination and hearing were normal. EEG was considered to be normal. Her karyotype was $46, \mathrm{XX}$ and no chromosomal abnormality was observed under standard growth conditions.

CASE 2

This girl was born in 1977 after an uneventful term pregnancy. She was the first child of a 16 year old mother who left her soon after birth. The father was unknown. Birth weight was $2030 \mathrm{~g}$, length $42 \mathrm{~cm}$, and OFC $32 \mathrm{~cm}$. Apgar score was 10 . Growth and psychomotor retardation was obvious from the first month of life. She suffered recurrent otitis media, bronchitis, and herpetic keratoconjunctivitis. At 7 months, a weight of $3840 \mathrm{~g}$, a length of $57 \mathrm{~cm}$, and an OFC of $41 \mathrm{~cm}$ were recorded. She spoke late, started walking at 4 years, and, at 11 years, was only able to decipher a few letters.

She was examined at the age of 11 (fig 5). She was $114 \mathrm{~cm}$ tall $(-4 \mathrm{SD})$, weighed $22 \mathrm{~kg}$, and had an OFC of $47.5 \mathrm{~cm}(-4 \mathrm{SD})$. Facial 

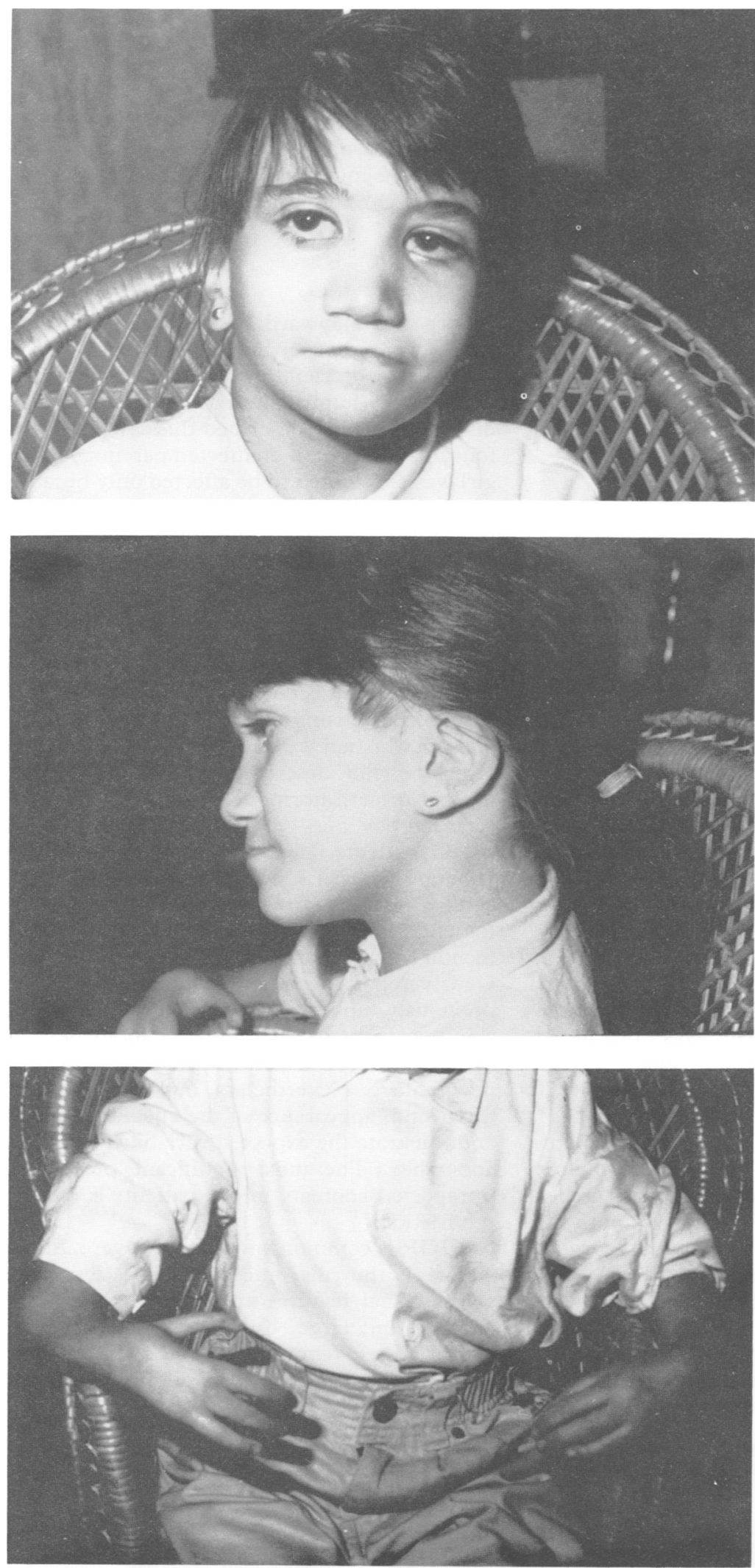

Figure 3 Patient 1: right forearm after surgery showing radial aplasia, elbow dysplasia, and fused carpal bones after surgery.

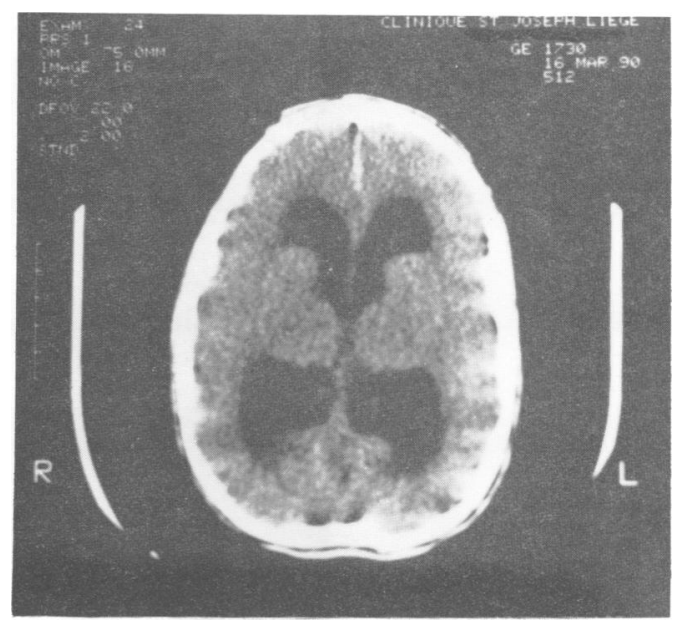

Figure 2 Patient 1 at 9 years. Note ptosis and shortened forearms. The right index finger was surgically displaced.

Figure 4 Patient 1: note enlarged ventricles.

dysmorphism included arched eyebrows, slight hypertelorism, slightly downward slanting palpebral fissures, slight ptosis, clouded right cornea (secondary to $\mathrm{HSV}$ infection), hyperopia and strabismus, broad and bulging nasal base, large, square nose (like a Greek

helmet), short philtrum, repaired right cleft lip and cleft palate, and thin, tapering thumbs which were proximally placed. A non-organic heart murmur was perceptible. A large cicatricial dimple was visible on each buttock over areas of muscular sclerosis (attributed to 


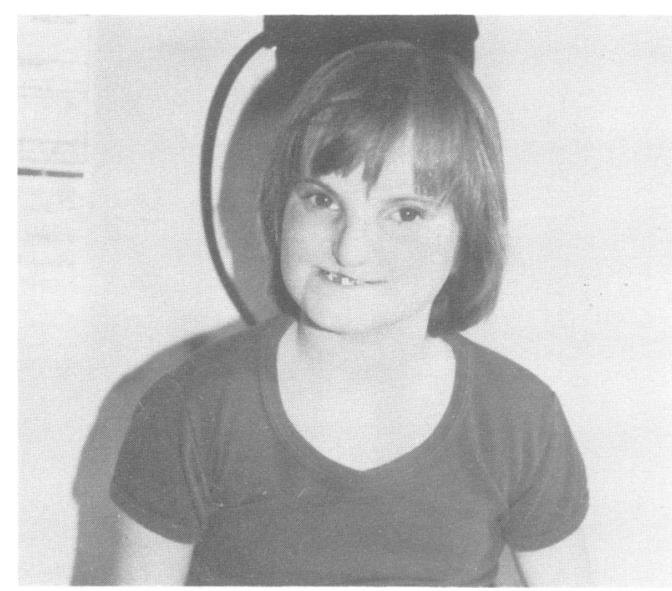

Figure 5 Patient 2: note hypertelorism and arched eyebrows.

intramuscular injection during infancy). She had a widely based, waddling gait, which was worsened by severe limitation of inner rotation of the hips. This was thought to result examination was otherwise normal.

Bone age was rated at 4 years when aged 8 years. Radiographs showed short first metacarpals and normal radii. Abdominal echotomography showed horseshoe kidneys. Audiometry, fundus examination, electromyogram, investigations of cellular and humoral immunity, and CT scan were normal. Chromosomes were normal.

CASE 3

This girl was the third child of normal, nonconsanguineous parents. She was born in the 38th week of an uneventful pregnancy. Birth weight was $2680 \mathrm{~g}$ and $O F C 31 \mathrm{~cm}$. At 20 months, she was $71 \mathrm{~cm}$ tall $(-3.5 \mathrm{SD})$, weighed $6500 \mathrm{~g}(-4 \mathrm{SD})$, and was microcephalic (OFC $42 \cdot 2 \mathrm{~cm}$ ). The face was slightly dysmorphic with slight hypertelorism, arched eyebrows, flat nasal root, and large mouth (fig 6). A submucous cleft palate required surgical repair. The ears were large and floppy. She had strabismus and hyperopia. Fundi were normal. The hair was fair and very thin. The hands were short, with large, very proximally inserted thumbs. There were deep palmar and plantar creases (fig 6). The nails were short and

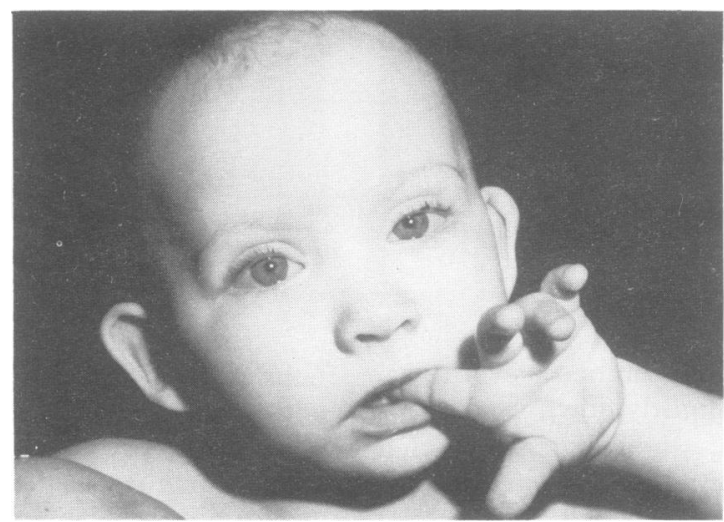
from muscle retraction. Neurological

concave. The left radial head was dislocated and extension and supination were limited. The anus opened into the vulvar fork. Developmental milestones were delayed. Ultrasonography disclosed horseshoe kidney. Radiographs of the hands were normal; bone age was 12 months at 18 months of age. CT scan and chromosome analysis were normal.

\section{Discussion}

Juberg and Hayward ${ }^{1}$ defined the syndrome with which their name is associated as the coexistence of cleft lip/palate, microcephaly, hypoplastic thumbs and radii, and radial head dislocation. They described this association in four of six sibs with unaffected parents. A fifth girl was considered to be affected only because of minor anomalies of the toes; this might now be considered to be one of the associated anomalies "occurring by chance, since they are not present in one of the two affected males and occur alone in one of the females". We agree with this opinion, and excluded her from the tabulation. In 21 years, only two other cases have been reported. Nevin et $a l^{2}$ broadened the spectrum of associated findings with one girl who had skull and vertebral anomalies. Kingston $e t a l^{3}$ described severe limb anomalies and growth hormone deficiency in a nonretarded boy.

Our patients fall into the general frame of Juberg-Hayward syndrome. Patient 2 is very similar to the previously reported cases. Patient 1 shows a severe phenotype and her mental retardation contrasts with the previously reported patients. She has two other previously undescribed features, ptosis and skin tag. In patient 3 , the hand anomalies are somewhat atypical and the anal anomaly is a new feature. Nevertheless, our cases confirm the overall appearance of the affected patients and illustrate the expected variability of radial anomalies. The most significant previously unreported anomaly in our patients is mental retardation.

IUGR is common and may be severe. Short stature is the rule; microcephaly is less constant. Facial features are characteristic: telecanthus and large, broad nose with parallel lateral edges, reminiscent of the 'Greek helmet' shape of $4 p-$ syndrome. The eyebrows are high, bowed, and generally upward slant-

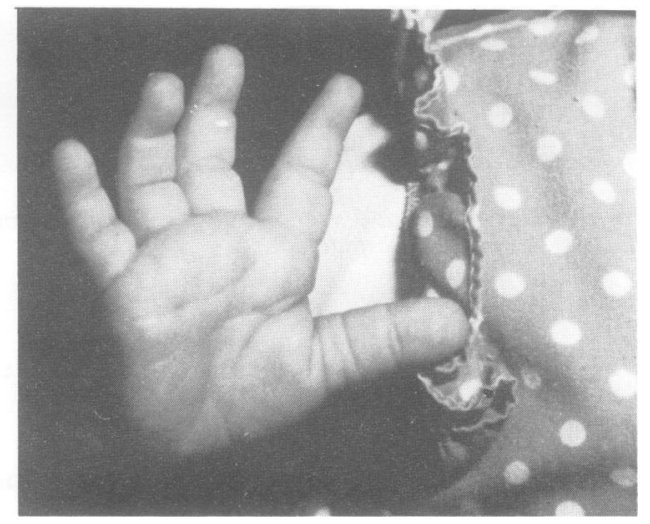

Figure 6 Patient 3. Note hypertelorism and arched eyebrows, and large thumb with deep creases.

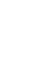

-


ing. Radial ray anomalies are uncommon but severe elbow involvement is observed even with minimal distal defect. There is an unusual frequency of horseshoe kidney and intellectual impairment is variable (table).

The differential diagnosis of Juberg-Hayward syndrome includes the VACTERL association, in which most of the malformations observed in Juberg-Hayward syndrome may be seen, but orofacial clefts are very uncommon, limb anomalies tend to be more asymmetrical, and there is no specific facial dysmorphism. Similar limb and renal malformations occur in Fanconi's anaemia, but facial dysmorphism and clefting are not observed in the latter. Our patients lack the hyperpigmented patches and the two older ones have no haematological anomalies. No chromosomal instability was noted. IUGR and upper limb reduction may suggest the diagnosis of Cornelia de Lange syndrome, but the facial features are clearly different and mental retardation is much less severe in the latter.
The genetics of the syndrome is not clear. The family of Juberg and Hayward ${ }^{1}$ suggests an autosomal recessive mode of inheritance, but advanced paternal age in some reports and extreme variability in expression could be pointers to autosomal dominant inheritance with reduced penetrance. As long as no other familial cases are known, genetic counselling of affected adults must be cautious. Prenatal diagnosis, though feasible in some cases, is likely to miss most of the moderately affected children, and absence of major radial defects is not reliable in predicting normal psychomotor outcome, as mental retardation is not correlated to the extent of the limb defect.

1 Juberg RC, Hayward JR. A new familial syndrome of oral, cranial and digital anomalies. F Pediatr 1969;74:755-62.

2 Nevin NC, Henry P, Thomas PTS. A case of the orocraniodigital (Juberg-Hayward) syndrome. $\mathcal{f}$ Med Genet 1981 18:478-80.

3 Kingston HM, Hughes IA, Harper PS. Orocraniodigital (Juberg-Hayward) syndrome with growth hormone deficiency. Arch Dis Child 1982;57:790-1.

Synopsis of $\mathfrak{F u b e r g - H a y w a r d ~ s y n d r o m e . ~}$

\begin{tabular}{|c|c|c|c|c|c|c|c|c|c|c|}
\hline & \multicolumn{4}{|c|}{ Juberg and Hayward } & \multirow{2}{*}{$\begin{array}{l}\text { Nevin } \\
\text { et } a l^{2}\end{array}$} & \multirow{2}{*}{$\begin{array}{l}\text { Kingston } \\
\text { et } a l^{3}\end{array}$} & \multicolumn{3}{|c|}{ This report } & \multirow[b]{2}{*}{ Total } \\
\hline & II. 2 & II. 4 & II. 5 & II.6 & & & 1 & 2 & 3 & \\
\hline Sex & $\mathbf{F}$ & $\mathrm{F}$ & $\mathbf{M}$ & $\mathbf{M}$ & $\mathbf{F}$ & $\mathbf{M}$ & $\mathbf{F}$ & $\mathrm{F}$ & $\mathbf{F}$ & $3: 6$ \\
\hline Birthweight (g) & 2730 & 2360 & 2130 & 2070 & 2160 & 1240 & 1440 & 2030 & 2680 & M:1857 \\
\hline Growth retardation & $\mathbf{N}$ & $\mathrm{N}$ & $\mathrm{Y}$ & $\mathrm{Y}$ & $\mathrm{Y}$ & $\mathrm{Y}$ & $\mathrm{Y}$ & $\mathrm{Y}$ & $\mathrm{Y}$ & $7 / 9$ \\
\hline Microcephaly & $\mathbf{N}$ & $\mathbf{Y}$ & $\mathbf{Y}$ & $\mathbf{Y}$ & $\mathrm{Y}$ & $\mathbf{N}$ & $\mathbf{Y}$ & $\mathbf{Y}$ & $\mathrm{Y}$ & $7 / 9$ \\
\hline Cleft lip & $\mathbf{Y}$ & $\mathbf{N}$ & $\mathrm{Y}$ & $\mathbf{Y}$ & $\mathrm{Y}$ & $\mathrm{Y}$ & $\mathbf{N}$ & $\mathbf{N}$ & $\mathbf{N}$ & $5 / 9$ \\
\hline Cleft palate & $\mathrm{N}$ & $\mathrm{N}$ & $\mathrm{Y}$ & $\mathrm{Y}$ & $\mathrm{Y}$ & $\mathrm{Y}$ & $\mathbf{N}$ & $\mathrm{Y}$ & $\mathrm{Y}$ & $6 / 9$ \\
\hline Bowed eyebrows & $\mathrm{Y}$ & & $\mathrm{Y}$ & & $\mathrm{Y}$ & $\mathbf{Y}$ & $\mathbf{Y}$ & $\mathbf{Y}$ & $\mathrm{Y}$ & $7 / 7$ \\
\hline Broad, flat nasal bridge & $\mathbf{Y}$ & & $\mathrm{Y}$ & $\mathbf{Y}$ & $\mathbf{Y}$ & $\mathbf{Y}$ & $\mathbf{Y}$ & $\mathrm{Y}$ & $\mathrm{Y}$ & $8 / 8$ \\
\hline Ptosis & & & & & $\mathrm{N}$ & $\mathbf{Y}$ & $\mathbf{Y}$ & $\mathrm{Y}$ & $\mathbf{N}$ & $3 / 5$ \\
\hline Cupped ears/preauricular tags & & & & & & & $\mathbf{Y}$ & $\mathbf{N}$ & $\mathrm{Y}$ & $2 / 3$ \\
\hline Thumb malposition/ankylosis & $\mathrm{N}$ & $\mathrm{Y}$ & $\mathrm{Y}$ & $\mathrm{Y}$ & $\mathbf{Y}$ & NA & NA & $\mathrm{Y}$ & $\mathbf{Y}$ & $6 / 7$ \\
\hline Thumb hypoplasia & $\mathbf{N}$ & $\mathrm{Y}$ & $\mathrm{Y}$ & $\mathbf{Y}$ & $\mathbf{N}$ & $\mathrm{Y}$ & $\mathrm{Y}$ & $\mathrm{Y}$ & $\mathbf{N}$ & $6 / 9$ \\
\hline Radial hypoplasia & $\mathbf{N}$ & $\mathbf{N}$ & $\mathbf{N}$ & $\mathbf{Y}$ & $\mathrm{Y}$ & $\mathrm{Y}$ & $\mathrm{Y}$ & $\mathbf{Y}$ & $\mathbf{N}$ & $5 / 9$ \\
\hline Elbow luxation/restriction & $\mathrm{N}$ & $\mathrm{N}$ & $\mathrm{Y}$ & $\mathbf{Y}$ & $\mathbf{N}$ & $\mathbf{Y}$ & $\mathrm{Y}$ & $\mathbf{N}$ & $\mathbf{Y}$ & $5 / 9$ \\
\hline Minor anomalies of toes & $\mathbf{Y}$ & $\mathbf{Y}$ & $\mathbf{N}$ & $\mathrm{Y}$ & $\mathrm{Y}$ & & $\mathbf{N}$ & & $\mathrm{Y}$ & $5 / 7$ \\
\hline Horseshoe kidneys & $\mathbf{N}$ & $\mathbf{N}$ & $\mathbf{Y}$ & $\mathbf{N}$ & & $\mathbf{N}$ & $\mathbf{N}$ & $\mathrm{Y}$ & $\mathrm{Y}$ & $3 / 8$ \\
\hline Kidney hypoplasia & $\mathbf{N}$ & $\mathbf{N}$ & $\mathbf{N}$ & $\mathbf{N}$ & & $\mathrm{Y}$ & $\mathbf{N}$ & $\mathbf{N}$ & $\mathbf{N}$ & $1 / 8$ \\
\hline Hydronephrosis & $\mathrm{N}$ & $\mathrm{N}$ & $\mathrm{N}$ & & & $\mathbf{N}$ & $\mathrm{Y}$ & $\mathbf{N}$ & $\mathrm{N}$ & $1 / 7$ \\
\hline Abnormal rib number & $\mathbf{N}$ & $\mathrm{N}$ & $\mathrm{Y}$ & $\mathrm{N}$ & & $\mathrm{Y}$ & $\mathrm{Y}$ & $\mathbf{N}$ & $\mathbf{N}$ & $3 / 8$ \\
\hline Abnormal spine/scoliosis & & & & & $\mathbf{Y}$ & $\mathbf{Y}$ & $\mathrm{Y}$ & $\mathbf{N}$ & $\mathbf{N}$ & $3 / 5$ \\
\hline Deafness & & & & & & $\mathbf{Y}$ & $\mathbf{N}$ & $\mathbf{N}$ & $\mathbf{N}$ & $1 / 4$ \\
\hline Mental retardation & & $\mathbf{N}$ & $\mathbf{N}$ & & $\mathrm{N}$ & $\mathbf{N}$ & $\mathrm{Y}$ & $\mathrm{Y}$ & $\mathbf{Y}$ & $3 / 7$ \\
\hline Brain atrophy & & & & & & & $\mathrm{Y}$ & $\mathbf{N}$ & $\mathbf{N}$ & $1 / 3$ \\
\hline $\begin{array}{l}\text { Abnormal pituitary fossa } \\
\text { hGH deficiency }\end{array}$ & & & & & $\mathrm{Y}$ & $\begin{array}{l}\mathbf{N} \\
\mathrm{Y}\end{array}$ & $\mathbf{N}$ & $\mathbf{N}$ & & $1 / 4$ \\
\hline
\end{tabular}

Y/N applies to clearly quoted or obviously recognisable features.

$\mathrm{NA}=$ not applicable. 